\title{
The Perceived Role of Risk And Resilience Factors Regarding Children in Middle Childhood's Psycho-Social Well-Being in a South African Rural High-Risk Community
}

\author{
Tebogo Mosang ${ }^{1}$ \& Izanette Van Schalkwyk ${ }^{1}$ \\ ${ }^{1}$ Centre for Child, Youth and Family Studies, COMPRES, North-West University, Potchefstroom, South Africa \\ Correspondence: Izanette van Schalkwyk, Centre for Child, Youth and Family Studies, North-West University, \\ Potchefstroom, South Africa. Orcid.org/0000-0002-8662-0897. Tel: 27-72-367-7739. E-mail \\ 20977026@nwu.ac.za
}

Received: August 18, 2019

Accepted: September 19, 2019 Online Published: September 27, 2019

doi:10.5539/jedp.v9n2p138

URL: http://doi.org/10.5539/jedp.v9n2p138

\begin{abstract}
Introduction: Middle childhood can be a period of significant challenges for many children as they may struggle to adapt to the demands of this life phase and their external environment. The external environment of the child is central for positive development and quality of life. However, the situation is even worse for children who live in a South African rural high-risk community, and are faced with numerous contextual vulnerabilities and multiple stressors related to poverty.

Method: This qualitative study used a qualitative descriptive research design and data were collected via individual interviews (parent participants) and focus group discussions (teacher participants). Thematic and content analysis were used allowing for an inductive process.

Findings: Findings displayed a mostly deficit mentality regarding children in middle childhood's psycho-social well-being. The first theme referred to the negative influences of the disempowering high-risk setting for the psycho-social well-being of children in middle childhood. The second theme indicated the possible dangers for family functioning. The third theme elucidated the role of the different stakeholders to lessen these environmental stressors and obstacles to ensure safety, stability, and children's well-being. Finally, specific components were given to intentionally protect and promote the psycho-social well-being of children in middle childhood in this community.
\end{abstract}

Limitation: Individual interviews with parent participants were mainly conducted with female participants; data obtained from male participants could add even richer information.

Recommendation: It is recommended that future research investigate the encouragement of the psycho-social well-being of children in middle childhood in this rural community by strengthening families' resilience.

Keywords: high-risk, middle childhood, psycho-social, resilience, well-being

\section{Introduction}

Children are at the heart of the 2030 Global Agenda, and the identified Sustainable Developmental Goals (SDGs) impact every aspect of a child's life (Hall \& Sambu, 2017). It is significant that this vision goes well beyond poverty eradication. These goals entail important matters for South African children, for example: focusing on health care; safe environments; child nutrition; and, creating enabling environments (taken from the Child Gauge, 2017, p. 19). The Government of South Africa has put in place a forward-looking system of laws and programmes to ensure basic support for children. Realizing the rights of children is pivotal to create a world of peace, equity, security, freedom, respect for the environment, and shared responsibility. Aida Girma (UNICEF South Africa Country Representative, 2016) called this, in short, "a world fit for children". In spite of significant efforts made by countries across the world towards achieving the Millennium Development Goals (MDGs), it is increasingly evident that South Africa's progress is uneven in many key areas.

The Magogong Village in Dr Ruth Segomotsi Mompati District, Greater Taung Local Municipality in the North-West Province of South Africa represents a blueprint of a rural high-risk environment, seeing that the typical indicators are present (see Felner, 2006), for example, poor housing; high levels of crime such as murder, sexual 
assault, robberies, substance abuse and addiction (mainly home brewed liquor, alcohol, marijuana), and violence (including domestic violence); school drop-outs; poor provision of care facilities for children; teenage pregnancies; various effects of poverty; high levels of unemployment as well as economic inactivity (including receiving grants from government); high exposure to HIV/AIDS due to risky behaviour; and child abuse and neglect (personal conversation with Mr Mompati Gabanakgosi, community development practitioner, Department of Social Development, 20 April 2017). Clearly, the context of a rural high-risk community is associated with multiple risks for children in middle childhood's development.

Khumalo, Temane, and Wissing (2012) stated that "environmental setting plays a major role in what one becomes" (p. 422). Bronfenbrenner's (1979) bio-ecological model emphasizes the key role of the environment in positive development, for example, the provision of daily needs such as water, food, housing, and sanitation. The environment of children in middle childhood is also essential for determining the accessible quality of education, possible prospects for employment, and quality of lifestyle (UNICEF, 2016). Therefore, socio-economic factors that determine living conditions cannot be omitted when discussing human settlement. Moreover, these issues are entwined with and related to differences in psycho-social well-being. Issues of context, culture, and life phase, such as middle childhood, are all associated with children's psycho-social well-being. In an article by East African Community (2017), psycho-social well-being is described as when individuals, families, or communities have cognitive, emotional, and spiritual strengths combined with positive social relationships.

\section{Rationale and Problem Statement}

Many studies on risk and resilience factors over decades indicate that the individual develops in continual interaction with the environment, including the family system, socio-cultural systems, and the physical environment (Bronfenbrenner \& Morris, 1998; Lerner, 2006; Masten, 2001, 2015). According to Ungar (2015), significant change in contexts where there are significant social, economic, and political challenges are needed for positive individual change. It is well documented that person and environment influence each other (Bronfenbrenner, 1979; Prilleltensky, Nelson, \& Peirson, 2001; Rosa \& Tudge, 2013). Since the social functioning of children in middle childhood is becoming increasingly important (Bennett, 2015) positive as well as negative peer pressure must be acknowledged. Negative peer pressure in the context of a rural high-risk community could imply many risks as to the psycho-social well-being of children in middle childhood (Beets, 2018). Yet, the influence of parents and educators as primary socialization agents is of key importance (Ungar, 2011). In this sense, an understanding of the "social ecology" of resilience as described by Michael Ungar (2011, p. 1) is significant.

Ungar (2015) emphasized the need to uncover the many protective as well as risk factors regarding children in middle childhood's psycho-social well-being to establish the ways in which they are enabled or obstructed to find their way to those vital psychological, social, cultural, and physical resources needed for sustainable well-being. His research highlighted the following factors as fundamental to children's resilient living: child cognitive ability, emotional regulation, parenting, low parental discord, and safe school and community environments. Although the negative outcomes in the lives of children such as the children in the Magogong Village who were in conflict with the law, dropping out of school, and showing at-risk behaviour, are specified (personal conversation with $\mathrm{Mr}$ Mompati Gabanakgosi, community development practitioner, Department of Social Development, 20 April 2017), the question arose regarding the risk and resilience factors linked to external forces of the environment in the selected community. Briefly put, various risk factors can all have short- and long-term consequences for children, families, and communities, wearying their ability to functioning well. On the other hand, research is also needed regarding the factors building and protecting youth's psycho-social well-being and acting as buffers for present and/or future difficulties in the South African context, in particular the Magogong Village (Masten, 2015).

Since there remains a significant gap between policy interventions and actual implementation (Patel \& Hochfeld, 2013), it is known that a lot of work is still required regarding the psycho-social well-being of children living in rural communities, This research aimed to give the selected rural high-risk community a voice regarding risk and protective factors about their children in middle childhood.

\section{Theoretical Framework}

The strengths perspective, systems theory, and Bronfenbrenner's bio-ecological theory - as well as taking into account developmental social work in South Africa - directed the current research. 


\section{Research Question and Aims}

\subsection{Research Question}

Based on the problem stated in the abovementioned section, the research question guiding the research was formulated as in the following manner 'What is the nature of the perceived risk and protective factors that play a role in the psycho-social well-being of children in middle childhood in a rural high-risk community?'

\subsection{Aim of the Study}

The research aimed to investigate via a qualitative approach the perceived role of risk and protective factors pertaining to the psycho-social well-being of children in middle childhood within the context of a rural high-risk community in the North-West Province of South Africa.

\section{Method}

\subsection{Research Approach and Design}

In this qualitative study, information was obtained via various qualitative methods and various groups of participants to explore the role of the perceived protective and risk factors in children in middle childhood's psycho-social well-being and the manifestations thereof within families, schools, and the wider community. There is an African proverb that says 'It takes a village to raise a child', highlighting the vital role of the community. Children get to a stage where they need to establish relationships outside of their family environment, such as when they start their school education during middle childhood.

\subsection{Participants}

In the selected community, namely the Magogong Village, signs of poverty are clear: there are informal dwellings, shacks, and brick houses (they still use pit toilets); there is electricity, but no running water in the yards; the community uses communal taps, while others have boreholes in their yards. There are backyard shebeens (informal drinking places operating without a liquor license); spaza shops (informal shops run at persons' homes selling household items, such as bread); and some taverns or pubs in the community. Different faith communities are active in this community; there is a community hall, but no recreational facilities or sports facilities for the youth; and the soccer grounds are self-made and not in a good condition. There are three schools in the rural high-risk community and each school accommodates about 300 learners. The population of this study consisted of parents and teachers who are important agents in regard to the psycho-social well-being of children in middle childhood (6 to 11 years of age) and who are residing and/or working in the selected high-risk rural community.

Once approval for the research was obtained from the health research ethics committee (HREC) of North-West University, the necessary permission was obtained from: i) the North-West Department of Education; ii) goodwill permission from the school principals of the three schools within this high-risk community; iii) the permission of the head leader of the community leaders in the community of Magogong village in Dr Ruth Segomotsi Mompati District; and, iv) the ward councillor of the community (representing the community leaders). The head leader or paramount chief oversees sixteen villages and she has community leaders in each community who are her assistants. They look into day to day challenges of the community and report back to her. Therefore, permission was obtained from the head leader of the community leaders (acting as a gatekeeper) of the selected community.

A gatekeeper for each of the two groups of participants was approached, namely i) parents; and, ii) teachers.

- The gatekeeper for the parents per school was a parent who is the chairperson of the school's governing body

- The gatekeepers for the teachers were the principal of the schools

The gatekeepers were informed by the researcher of the planned study and these persons appointed a mediator per participant group in order to recruit possible participants.

- A mediator for the parents per school was a parent who is part of a school's governing body for parents;

- The mediators for teachers per school were head of departments

The appointed mediators (by the gatekeepers) of the two groups were asked to approach potential participants in the various groups. Convenient sampling was used and potential participants were approached by appointed mediators who explained to them matters related to the purpose of the research and matters regarding participation as described in the consent forms.

Participant group 1: Parents. Semi-structured interviews were conducted with 36 parents in the community who complied with inclusion criteria. 
Inclusion criteria for parent participants:

- You are a parent in the community

- You are the biological or legal foster parent of this child

- You have a child in middle childhood (between 6-11 years old) at a primary school in the Magogong Village

- You have experience of living in this high-risk rural community (more than five years)

- You are male or female (gender)

- Your participation is voluntarily

- You are willing to be (digitally) voice recorded

Participant group 2: Teachers. Focus group discussions were conducted with 24 teachers of two schools in the selected community who complied with the inclusion criteria.

Inclusion criteria for teacher participants:

- Participant is a teacher in the community

- Participant has experience of working with children in middle childhood (you have at least five years teaching experience, teaching learners between grade 1 and grade 6

- Participant has experience of working in a high-risk rural community (more than two years)

- Participant is male or female (gender)

- Participant's participation is voluntarily

- Participant is willing to be (digitally) voice recorded

- Socio-demographic information of participants was also obtained in order to provide a profile of the participants via a short demographical questionnaire.

The researcher used a qualitative descriptive design as the aim of the research study was to investigate and explore the perceived role of protective and risk factors (i.e., the research design as the 'how' of the study') pertaining to the psycho-social well-being (i.e., the 'what') of children in middle childhood ('who') in the context of a rural high-risk environment ('where').

\subsection{Data Collection}

Personal one-on-one semi-structured interviews were used for collecting data from the parents (a total number of thirty six parents) and a focus group discussion was held with a group of teachers (a total number of twenty-four teachers). Each participant was asked to complete a demographic questionnaire of nine demographic questions in a closed-ended format before commencement of the data collection opportunity. Arrangements were made with the assistance of the mediator for parent participants to complete the demographical questionnaires where parent participants were illiterate. The questionnaire was used to provide a profile of the participants and was not part of the analysed data.

The semi-structured interviews involved open-ended questions intended to elicit views and opinions from the participants (Creswell, 2013), and the researcher took care to obtain information that is context-sensitive (Ungar, 2015). An interview guide was used and individual interviews were audio-recorded (Rabionet, 2011) with the participants' permission. After data gathering had been concluded, the recordings were transcribed. The text was then translated from Tswana to English. Throughout the process of data gathering, the researcher kept field notes as well as a reflexive diary.

\subsection{Ethical Concerns}

The research proposal was approved by the research focus area Community Psychosocial Research (COMPRES) of the Faculty of Health Sciences at the North-West University, where after ethical approval to conduct the study was obtained from the Health Research Ethics Committee (HREC) of the North-West University (ethical approval number: NWU-00006-18-S1). Written permission to conduct the study was obtained from the Department of Education of the North-West Province as well as school principals of the participating schools. The following ethical principles guided the research process: obtaining written informed consent prior to data collection; participants had the freedom to withdraw at any time; no harm was foreseen; and confidentiality and anonymity were ensured. The risk level of the participants was considered as medium risk and measures to minimize risk were in place. 


\subsection{Data Analysis}

Although systems theory, with particular reference to Bronfenbrenner's bio-ecological model, was used as a theoretical framework, it is not a given that the risk and protective factors are known to the researchers. Therefore, it is argued that thematic and content analyses were relevant for the purpose of this study, allowing for a more inductive process. The transcriptions of the collected data via the personal interviews and focus group discussions represented the textual data that were analysed.

Semi-structured interviews (group 1 - parents). A thematic analysis was used (Braun \& Clarke, 2006) and key themes were identified. Data were analysed following the six steps described by Braun and Clarke (2013). These are: immersion in data to become familiar with the breadth of the data, developing initial codes, searching for themes, reviewing themes, naming and defining themes, and finally, writing a report. The thematic analysis was conducted manually and not through a computer program. Briefly put, in this qualitative analysis, thematic analysis was conducted in an inductive, explorative way by identifying themes (cf. Braun \& Clarke, 2013). Thematic analysis was used for the analysis of the data collected via semi-structured interviews.

Focus group discussions (group 2 - teachers). Content data analysis was used as described by Tesch (as cited in Creswell, 2009) as this analysis strategy allows the researcher to stay close to the data to describe the phenomenon (Colorafi \& Evans, 2016), specific steps were followed and to identify categories and code.

Finally, the two sets of data, namely the identified data material of the interviews and the FGDs that fall under the one category or theme; were combined and integrated to offer the findings of the study. A co-coder was assigned, namely a trained person with the needed experience, to enhance the initial coding. The use of more than one type of analysis strengthened the rigor and trustworthiness of the findings via methodological triangulation. Taking into account that data analysis happens alongside data collection in qualitative research, much analytical work had to be done once the researcher has left the research field. Data analysis was grounded in and supported by existing literature to guide this aspect of the research process to answer the research question.

\section{Findings and Discussion}

\subsection{Demographic Information (Teachers and Parents)}

Socio-demographic information of both participant groups (parents and teachers) was obtained in order to provide a profile of the participants via a short demographical questionnaire; the information is presented in the Table 2 below.

Table 2. Socio-demographic information of participants (teachers and parents)

\begin{tabular}{llll}
\hline Category & Response & Frequency & Percentage \\
\hline \multirow{2}{*}{ Gender } & Male & 18 & $30 \%$ \\
& Female & 42 & $70 \%$ \\
\hline \multirow{4}{*}{ Age } & $20-29$ years & 6 & $10 \%$ \\
& $30-39$ years & 10 & $17 \%$ \\
& $40-49$ years & 28 & $47 \%$ \\
\hline \multirow{2}{*}{ Relationship with the children under study (age 6-11 years) } & $50-59$ years & 12 & $20 \%$ \\
& G0 years and above & 4 & $6 \%$ \\
\hline & Biological parents & 22 & $37 \%$ \\
& Foster parent/legal guardian & 5 & $8 \%$ \\
& Grandparent & 9 & $15 \%$ \\
& Teacher & 24 & $40 \%$ \\
\hline \multirow{3}{*}{ Highest qualification } & Grade R-3 & 2 & $3 \%$ \\
& Grade 4-7 & 3 & $5 \%$ \\
& Grade 8-11 & 23 & $38 \%$ \\
& Grade 12 & 8 & $13 \%$ \\
& Diploma/ FET qualification & 11 & $18 \%$ \\
& University degree & 13 & $23 \%$ \\
\hline
\end{tabular}




\begin{tabular}{|c|c|c|c|}
\hline \multirow{4}{*}{ Number of years stayed in the community } & $0-5$ years & - & - \\
\hline & $5-10$ years & 7 & $12 \%$ \\
\hline & $10-20$ years & 15 & $25 \%$ \\
\hline & 30 years or more & 38 & $63 \%$ \\
\hline \multirow{6}{*}{ Home language } & Setswana & 55 & $91 \%$ \\
\hline & Xhosa & 3 & $5 \%$ \\
\hline & Zulu & - & \\
\hline & Afrikaans & - & \\
\hline & Venda & 1 & $2 \%$ \\
\hline & Sotho & 1 & $2 \%$ \\
\hline \multirow{5}{*}{ Type of household in the community } & Single-parent household & 33 & $55 \%$ \\
\hline & Married parents & 20 & $33 \%$ \\
\hline & Divorced & - & - \\
\hline & Co-habiting & 3 & $5 \%$ \\
\hline & Grandparents & 4 & $7 \%$ \\
\hline \multirow{3}{*}{ Family's main source of income } & Social grants & 30 & $50 \%$ \\
\hline & Temporary work/odd jobs & 4 & $7 \%$ \\
\hline & Permanent employment & 26 & $43 \%$ \\
\hline \multirow{4}{*}{ Household's monthly income } & Less than R1500 & 27 & $45 \%$ \\
\hline & R1500-R3000 & 9 & $15 \%$ \\
\hline & R3000-R5000 & - & - \\
\hline & R5000 and above & 24 & $40 \%$ \\
\hline
\end{tabular}

In this section, the findings of this qualitative study are presented as the main and sub-themes which were identified. Data obtained via two participant groups (parents and teachers) were integrated.

An exploration and description of risk and protective factors (sometimes referred to as resilience factors that play a role in the psycho-social well-being of children in middle childhood living in a south African high-risk community are presented.

\subsection{Main Themes and Sub-Themes}

Table 3 below summarizes the main themes and sub-themes that were identified.

Table 3. Summary of main and sub-themes

\begin{tabular}{ll}
\hline Themes & Sub-themes \\
\hline $\begin{array}{l}\text { Theme 1: Negative influences of a disempowering setting } \\
\text { (threats to the psycho-social well-being of children in } \\
\text { middle childhood in a disempowering setting) }\end{array}$ & $\begin{array}{l}\text { Risks in the community that threaten the well-being of children } \\
\text { between } 6 \text { and11 years } \\
\text { community } \\
\text { Sub-theme 1.2 Children in middle childhood being exposed to an } \\
\text { unhealthy and negative lifestyle }\end{array}$ \\
\hline $\begin{array}{l}\text { Theme 2: Dangers for families/family functioning } \\
\text { threatening the psycho-social well-being of children in }\end{array}$ & $\begin{array}{l}\text { Sub-theme 2.1 Dangers of families and unemployment } \\
\text { Sub-theme 2.2 Dangers of poor family functioning } \\
\text { middle childhood) }\end{array}$ \\
\hline $\begin{array}{l}\text { Theme 3: Role of different stakeholders (parents, } \\
\text { teachers, social workers, churches, community leaders, } 2.3 \text { Dangers of child-parent households } \\
\text { and government) in addressing or lessening the obstacles } \\
\text { to ensure safety, stability, and well-being }\end{array}$ & $\begin{array}{l}\text { Sub-theme } 3.1 \text { Parents' involvement in the lives of their children } \\
\text { improving the psycho-social well-being of children in a high-risk } \\
\text { community }\end{array}$ \\
\hline
\end{tabular}


Resources in families to be developed

Theme 4: Intentional promotion of children in middle childhood's psycho-social well-being

Positive factors in the families that encourage children
Parents should monitor their children

Parents to instill discipline in their children

Parents to be involved in their children's lives

Community needs recreational facilities

Nothing to entertain the children in the community

Theme 1: Negative influences of a disempowering setting. The first theme is about the various risks that children in middle childhood are exposed to on a daily basis in the Magogong community. All participants emphasized the negative influences of this disempowering setting. Teachers and parent participants referred to these contextual influences with despondency, since the youngsters of this community are continuously exposed to so many perils associated with crime and violence, as well as to unhealthy lifestyles such as the abuse of alcohol.

Sub-theme 1.1: Safety issues. Participants explained that there is a high rate of crime in the community, such as kidnapping, robbery, housebreaking, rape and murder.

"In our community there is a high rate of house breakings and mugging, especially if you move around alone in the evenings. It is really not safe" (personal interview, school 1, participant 3, female, Tswana).

Children in middle childhood are exposed to many risks in this rural high-risk community and these risks, for example, incidences of crime, are a real threat to their safety. Apart from the likely possibility of being victims of crime, children are also witnessing these acts of violence frequently, with serious consequences for their psycho-social well-being (UNICEF, 2014). Consequently the high crime rate in South Africa limits these children to achieve their potential (National Development Plan [NDP], 2030). Curtis, Waters, and Brindis (2011) indicate the possible dangers of rural environments if youth are exposed to risks such as violence and limited health services. Although violence against women and children may take many forms (e.g. physical, sexual, economic, or psychological), all of these represent a violation of human dignity and human rights (UNICEF, 2014).

Sub-theme 1.2: Children in middle childhood being exposed to an unhealthy lifestyle. All participants referred to the abuse of substance, for example, alcohol and other illegal drugs as damaging examples of an unhealthy lifestyle for children in middle childhood. In some families in this community, both parents abuse alcohol.

"In these taverns, you find people that drink alcohol, men and women. So these kids see this and they view it as something that they can also do. So they also start drinking alcohol" (personal interview, school 2, participant 1, female, Tswana).

The visibility of many sites where substance use occurs in this rural community creates a culture of 'it is okay'. Apart from being exposed to, for example, alcohol abuse, the impact of these unhealthy lifestyles has far-researching consequences. Existing research indicates that when children are exposed to their parents' substance-abusing habits, then it is highly likely that these children will have alcohol- and drug-abuse problems themselves by adolescence or in young adulthood (Solis, Shaur, Burns, \& Hussong, 2012; Van Schalkwyk, 2019). The White Paper on Families in South Africa (Department of Social Development, 2013) emphasizes the importance of competent families versus the damaging impact of 'broken families' when children are exposed to unhealthy lifestyles. Risks for children whose parents or caregivers are substance-abusers are well-documented (Jamieson \& Richter, 2017), such as the greater risk of being exposed to violence, exploitation, and neglect. According to the United Nations (2016), every child has a right to be cared for by their parents.

Theme 2: Dangers for families or family functioning (threatening the psycho-social well-being of children in middle childhood). 'Families at risk' refer to those families who - for whatever reason - may find it difficult to keep their children safe. Unemployment, poverty, substance abuse, and violence are major risk factors associated with child abuse and neglect (World Childhood Foundation, 2018). Both groups of participants, namely parents and teachers, referred to the dangers in the high-risk community for families and the implications thereof for family functioning.

Sub-theme 2.1: Dangers of families and unemployment. Participants spoke freely about the high levels of unemployment in this community and that most families depend on social grants for survival.

"There is a lot of unemployment in the families. Poverty is a problem, even though they receive child support grants it is not enough." (Personal interview, school 1, participant 2, female, Tswana)

"There is also high unemployment in the community a lot of families only depend on grants" (personal interview, 
school 3, participant 2, female, Tswana).

A South African study conducted by Ferrer and Visser (2015) show that poverty; underdevelopment; ill-health; and, psychological distress are strongly associated with unemployment in rural areas. Izaks, Avenant, and van Schalkwyk (2017) found that the difficulties associated with unemployment are not only limited to financial issues, but comprise a range of physical, emotional, and psychological problems for parents and their offspring. Holborn and Eddy (2011) signpost these as 'warning signs' when families who experience unemployment are living in extreme poverty, since these family units are associated with dysfunctional family environments. This finding is also supported by Ward et al. (2015) who indicate the serious effects of poverty, since people living in poverty are likely to be poorly educated and thus less able to support their children's educational development. Poverty, therefore, can significantly undermine parenting, decrease the life chances of children, and thereby transmit poverty from one generation to the next (Ward et al., 2015).

Sub-theme 2.2: Dangers of poor family functioning. Families are the immediate setting for the growth and development of children in middle childhood (compare micro level, Bronfenbrenner, 1979; Rosa \& Tudge, 2013). There are many examples in this high-risk rural community of how parental practices suffer in regard to healthy discipline. There are variations in how parents raise their children in rural high-risk community. Many parents in the selected community were viewed as uninvolved in the lives of their children (in terms of their parenting) (cf Dakers, 2018).

"Parents are unable to control their children. There is no discipline in other families, children do as they please" (personal interview, school 2, participant 6, female, Tswana).

The social workers and the schools are trying to get parents involved in the lives of their children without producing any positive results. An assumption can be made that the reason for the parents' behaviour might be because they themselves did not receive a proper upbringing or parental guidance. This means that these parents allow their children ample freedom, and little or no discipline is applied. Teacher participants referred to the misbehavior of children of uninvolved parents and these learners' cognitive and emotional problems. These parental practices could indicate poor quality of the parental relationship with children in middle childhood and are related to low life satisfaction (Tobergte \& Curtis, 2013).

Sub-theme 2.3: Dangers of child-parent households. A child-only household is defined as a household in which all members are younger than 18 years (Child Gauge, 2017). These households are also commonly referred to as 'child-headed households', and the Children's Act definition of a child-headed household includes households where there are adults who may be too sick or too old to effectively head the household, and a child over 16 years bears this responsibility. Child-headed households are a reality in many South African communities, and these households are associated with a high incidence of adult illness and deaths due to AIDS (Jamieson, Berry, \& Lake, 2017).

"Some of the households' parents are deceased due to HIV/AIDS and children are left on their own and relatives refuse to help to take care of these children. These children are at risk of being exploited as they do not have adult supervision." (Personal interview, school 2, participant 7, female, Tswana).

The presence of child-headed households in this community marks an increased possibility that children are exposed to sexual abuse, the effect of poverty on children, and the breaking down of family functioning - they do not grow up in safe and secure families. The overall impact is coined by Holborn and Eddy (2011) as 'fractured families', where children in middle childhood do not experience quality relationships of love and nurturance, security, responsive interaction, and encouragement for exploration.

Theme 3: Role of different stakeholders. The participants spoke in general about their opinions about the roles different stakeholders should play in addressing or lessening the obstacles to ensure safety, stability, and well-being for their children in middle childhood. Many of the participants believed that parents are the most important people in ensuring the safety of their children before any other people.

"Parents need to play an active role in the upbringing of their children" (personal interview, school 1, female participant 3, Tswana).

"Us as parents we need to be good role models of our children" (personal interview, school 3, participant 12, female, Tswana).

The participants were in agreement that, in the past, when a person saw a child doing something wrong or getting into danger, they stepped in to intervene even before they could ask the child's parents. They practiced Ubuntu by showing humanity and compassion towards others in daily functioning. Currently the role of different stakeholders 
was stressed:

- The role of the government and safety matters

- To increase the number of social workers in high-risk community

- To foster the meaning of the church and spiritual well-being again in this community

- To obtain the confidence and hope in community leaders and government again

- To ensure children's rights within the family by teaching parenting of today and tomorrow about children's rights, and to support parents more actively in the hard work of raising their children.

In South Africa, there are days set aside to raise awareness on the importance of looking after children and ensuring that children's rights are protected. There is, for example, Child Protection Week, Children's Day, and 16 days of activism of no violence against women and children. The Children's Act 38 of 2005 clearly states that it is the responsibility of everyone to report any abuse or ill-treatment done to a child by anyone (The Convention on the Rights of the Child, UNICEF). Seemingly, the participants highlighted the role of the government and its responsibility to put in place all available measures to make sure children's rights are respected, protected, and fulfilled. The lack of assets in the community was also stipulated as a hindrance to the healthy development of children in middle childhood.

"Truly speaking there is nothing. Our community does not have any facility that children can go to after school. There is nothing positive our children are benefiting from our community except learn of the crimes that are taking place here" (personal interview, school 1, participant 4, female, Tswana).

The third main theme concerns the role that the various stakeholders can play in addressing the obstacles in the lives of children in middle childhood, namely parents, teachers, social workers, churches/faith communities, community leaders, and the government.

Theme 4: Intentional promotion of children in middle childhood's psycho-social well-being. Children who attend school are in a better position than those who do not, as school offers them opportunities towards academic and social success.

"Schools are the only thing that is keeping our children safe" (personal interview, school 1, participant 1, female, Tswana).

The positive influence of schools in rural high-risk community is even more important as they offer resources for learners and parents to take part in practices of well-being (Mathews et al., 2014). A practical example is that children whose parents are involved in their schooling tend to do better at school and feel that education is important. Parents' involvement in their children's schooling includes ensuring that the child does their homework, attending parent teacher meetings, and participating in school activities.

The school prepares children to become problem-solvers and solution-seekers. The skills that children acquire at school will assist them in their adulthood (Faith, 2012). Grimova and Van Schalkwyk (2016) describe a positive school climate in terms of an enabling environment for optimal functioning, and those positive psychological markers promoting relational well-being aimed at respectful interactions. The promotion of enabling schools (see Ebersöhn et al., 2018) suggests much more than just a space of safety; schools are also areas for the encouragement of learners in middle childhood's academic and life success, as well as developing parents' positive parenting (Wessels, 2012).

In summary, the main themes of the current research illustrate in no uncertain terms the many risks for children in middle childhood's psycho-social well-being in the Magogong Village in Dr Ruth Segomotsi Mompati District, Greater Taung Local Municipality in the North West Province of South Africa. The first two themes display the negative or disempowering influences of this setting, with reference to safety issues, children's exposure to substance abuse, and the dangers for families and family functioning associated with poverty and high crime. Research studies support the major role of environmental setting for positive development (Khumalo et al., 2012; Ungar, 2015; Van Schalkwyk, 2019). Ultimately, the risks associated with living in a high-risk community comprise much more than material deprivation and "poverty traps" (Burger et al., 2014), it also brings about suffering from worth deprivation (Prilleltensky $(2004 ; 2012$; 2019). The remaining themes raise the possible resources towards protective factors in this community. While a contextual understanding of structural conditions for the need for a social justice approach to positive development is vital, research also indicates that all communities have strengths and resources (Lazarus, Seedat, \& Naidoo, 2017). However, a deficit mentality seemed to override, seeing that resources were viewed mostly in terms of lesser risks. These findings were guided by the theoretical frameworks of the qualitative study, namely that an ecological stance aided by systems theory is 
vital when looking at a particular life phase (children in middle childhood) and psycho-social well-being.

\section{Recommendations}

It is recommended that future research look at effective interventions within the South African context to strengthen children in middle childhood's psycho-social well-being via the empowering of South African families as well as strengthening children's psychological well-being. Findings refer to the role of parents and teachers (participants), but a strengths perspective could allow those particular strengths, for example, children in middle childhood's competencies regarding self-regulation and school success. Also, since an ecological understanding implies children in middle childhood's development in context, these efforts should include all relevant stakeholders in the particular community.

\section{Conclusion}

The purpose of this research was to explore the perceived role of risk and resilience factors regarding children in middle childhood's psycho-social well-being in a South African rural high-risk community. In answer to the research question the findings exposed a mostly deficit mentality regarding children in middle childhood's psycho-social well-being in this setting. Although rather upsetting, this mostly negative perspective of the participants about children in middle childhood's psycho-social well-being in their rural high-risk community was clear. The findings indicated that numerous risk factors are present in this rural high-risk community (such as lack of parental involvement in the lives of children, alcohol and drug abuse within families and in the community, a high crime rate, poverty, and unemployment). These risks are part of the daily functioning and interactions of children in middle childhoods' primary settings for growth or development. In the South African context, the negative influences of these risks are well documented, with the link to high school drop-out and various other social problems adding to an accumulation of risks in that particular family or community. Finally, the desperate need to increase the effects of those resilience (protective) factors within and across spheres was voiced to the support of the psycho-social well-being of children in middle childhood. Evidently the entire rural high-risk community needs to be empowered to use their assets and strengths to address risk and managing their protective resources. This viewpoint holds that people are enabled to individually and collectively negotiate for those resources to be provided in culturally meaningful ways.

The world today is confronted with a painful but irrefutable truth that millions of children are suffering for no other reason than the country, the community, the gender, or the circumstances into which they are born. There is no doubt that also this South African community is regarded as dangerous or a 'not-child-friendly space' with its high-risk and high-need. Children in middle childhood in the Magogong community's psycho-social well-being are affected in an unimaginably detrimental way. The scars and trauma experienced in childhood if not addressed can be irreversible. While a serious lack of community assets, poor family functioning, and even limitations in schooling are clear, this investigation serves as a signpost for imminent and immediate action towards the attainment of the 2030 SDG's in the Magogong community as 'a world fit for children'.

\section{References}

Beets, S. (2018). A well-being programme to enhance learners in middle childhood's social Skills (Unpublished doctoral thesis, North West University: Potchefstroom).

Bennett, J. R. (2015). Addressing well-being in early and middle childhood: Recreation therapy interventions aimed to develop skills for a healthy life (Master's thesis, University of Utah, Utah). https://doi.org/10.18666/TRJ-2016-V50-I1-6782

Braun, V., \& Clarke, V. (2006). Using thematic analysis in psychology. Qualitative Research in Psychology, 3(2), 77-101. https://doi.org/10.1191/1478088706qp063oa

Braun, V., \& Clarke, V. (2013). Successful qualitative research: A practical guide for beginners. California, CA: SAGE.

Bronfenbrenner, U. (1979). The ecology of human development. Cambridge, MA: Harvard University Press.

Bronfenbrenner, U., \& Morris, P. A. (1998). The ecology of development processes. In W. Burger, R., Van der Berg, S., Gustafsson, M., Adams, C., Coetzee, M., Moses, E., ... Zoch, A. (2014). Poverty traps and social exclusion among children in South Africa, A Report to the South African Human Rights Commission. https://doi.org/10.1017/CBO9781107415324.004

Creswell, J. W. (2009). Research design: Qualitative and quantitative and mixed methods approaches (3rd ed.). Los Angeles, CA: SAGE. 
Creswell, J. W. (2013). Qualitative inquiry and research design: Choosing among five approaches (3rd ed.). Thousand Oaks, CA: SAGE.

Davies, D. (2011). Child development: A practitioner's guide (3rd ed.). New York, NY: The Guilford Press.

Department of Social Development. (2013). White paper on families in South Africa. Pretoria: Government Printers.

East African Community. (2017). 2nd EAC Child Rights Conference. Retrieved from https://www.eac.int/gender/children/84-sector/gender

Ebersöhn, L., Loots, T., Mampane, R., Omidire, F., Malan-Van Rooyen, M., Sefotho, M., \& Nthontho, M. (2018). An indigenous psychology perspective on psychosocial support in Southern Africa as collective, networking, and pragmatic support. Journal of Community \& Applied Social Psychology, 1-16. http://doi.org/10.1002/casp.2371

Faith, R. (2012). The school's role in influencing child development. Retrieved from https://mom.me/kids/4978-what-school-role-influencing-child-development/

Farley, O. W., Smith, L. L., \& Boyle, S. W. (2006). Introduction to social work (10th ed.). USA: Pearson Education Inc.

Felner, R. D. (2006). Poverty in childhood and adolescence. In S. Goldstein \& R. B. Brooks (Eds.), Resilience in children (pp. 125-148). New York, NY: Springer. https://doi.org/10.1007/0-306-48572-9_9

Ferrer, S., \& Visser, M. (2015). Farm workers' living and working conditions in South Africa: Key trends, emergent issues, and underlying and structural problems. Institute of Development and Labour Law. University of Cape Town. Retrieved from http://idll.uct.ac.za

Geldenhuys, O. (2016). Relational well-being of a group of adolescents in a South African high-risk community (Unpublished doctoral dissertation). North-West University, Potchefstroom.

Grimova, L., \& Van Schalkwyk, I. (2016). Learners' perceptions and experiences of respect in educator-learner relationship. Journal of Psychology in Africa, 26(3), 1-8. http://doi.org/10.1080/14330237.2016.1185914

Hall, K., \& Sambu, W. (2017). Demography of South Africa's children. South African Child Gauge. Retrieved from http://www.ci.uct.ac.za/sites/default/files/image_tool/images/367/Child_Gauge/South_African_Child_Gaug e_2017/Child_Gauge_2017_lowres.pdf

Helmer, M., Pulla, V., \& Carter, E. (2015). Social work and diversional therapy: Common Threads from a strengths perspective social work and diversional therapy. International Journal of Social Work and Human Services Practice, 2(6), 297-302.

Holborn, L., \& Eddy, G. (2011). First steps to healing the South African family. Johannesburg: SAIRR.

Jamieson, L., Berry, L., \& Lake, L. (2017). South African Child Gauge 2017. Cape Town: Children's Institute, University of Cape Town.

Jamieson, L., \& Richter, L. (2017). Striving for the Sustainable Development Goals: What do children need to thrive? In L. Jamieson, L. Berry, \& L. Lake. (Eds.), South African Child Gauge 2017 (pp. 32-42). Cape Town: Children's Institute, University of Cape Town.

Khumalo, I. P., Temane, Q. M., \&Wissing, M. P. (2012). Socio-demographic variables, general psychological well-being and the Mental Health Continuum in an African context. Social Indicators Research, 105(3), 419-442. http://doi.org/10.1007/s11205-010-9777-2

Lazarus, S., Seedat. M., \& Naidoo, A. (2017). Community Building: Challenges of Constructing Community. In M.A Bond, I.S. Serrano-Garcia \& C.B. Keys (eds.), APA Handbook of Community Psychology (Vol. 2), Methods for Community Research and Action for Diverse Groups and Issues (pp. 215-234). Washington DC: American Psychological Association. https://doi.org/10.1037/14954-013

Lerner, R. (2006). Resilience as an attribute of the developmental system: Comments on the papers of Professors Masten and Wachs. Annals of the New York Academy of Sciences, 1094, 40-51. https://doi.org/10.1196/annals.1376.005

Liddle, H. A., \& Hogue, A. (2000). A family-based, developmental-ecological preventive intervention for high-risk adolescents. Journal of Marital and Family Therapy, 26(3), 265-279. http://doi.org/10.1111/j.1752-0606.2000.tb00297.x 
Masten, A.S. (2001). Ordinary magic: Resilience processes in development. American Psychologist, 56(3), 227-238. https://doi.org/10.1037/0003-066X.56.3.227

Masten, A. S. (2015). Ordinary magic: Resilience in development. New York, NY: The Guilford Press.

Mathews, S., Jamieson, L., Lake, L., \& Smith, C. (2014). South African Child Gauge. Cape Town: Children's Institute, University of Cape Town.

Meinck, F., Cluver, L. D., \& Boyes, M. (2013). Orphanhood and household sickness as predictors of physical, emotional \& sexual child abuse. European Regional Conference on Child Abuse \&Neglect. ISPCAN, Dublin.

Prilleltensky, O. (2004). My child is not my carer: Mothers with physical disabilities and the well-being of children. Disability and Society, 19(3), 209-223. https://doi.org/10.1080/0968759042000204185

Prilleltensky, I. (2012). Wellness as fairness. American Journal of Community Psychology, 49(1-2), 1-21. https://doi.org/10.1007/s10464-011-9448-8

Prilleltensky, I. (2019). Mattering at the Intersection of Psychology, Philosophy, and Politics. American Journal of Community Psychology, 0, 1-19. https://doi.org/10.1002/ajcp.12368

Prilleltensky, I., Nelson, G., \& Peirson, L. (2001). The role of power and control in children's lives: An ecological analysis of pathways toward wellness, resilience and problems. Journal of Community and Applied Social Psychology, 11, 143-158. https://doi.org/10.1002/casp.616

Rabionet, S. E. (2011). How I learned to design and conduct semi-structured interviews: An ongoing and continuous journey. The Qualitative Report, 16(2), 563.

Rosa, E. M., \& Tudge, J. (2013). Urie Bronfenbrenner's theory of human development: Its evolution from ecology to bioecology. Journal of Family Theory \& Review, 5, 243-258. https://doi.org/10.1111/jftr.12022

Seligman, M. E. P. (2011). Flourish: A visionary new understanding of happiness and well-being. New York, NY: Simon \& Schuster.

Solis, M. J., Shadur, M. J., Burn A. R., \& Hussong, A. M. (2012). Understanding the diverse needs of children whose parents abuse substances. https://doi.org/10.2174/1874473711205020135

Tobergte, D. R., \& Curtis, S. (2013). Handbook for positive psychology in schools. Ungar, M. (2011). The social ecology of resilience: Addressing contextual and cultural ambiguity of a nascent construct. The American Journal of Orthopsychiatry, 81(1), 1-17. https://doi.org/10.1111/j.1939-0025.2010.01067.x

Ungar, M. (2015). Working with children and youth with complex needs: 20 skills to build resilience. New York, NY: Routledge.

UNICEF. (2016). South Africa's children: A review of equity and child rights.

Van Schalkwyk, I. (2019). Strengthening female-headed households: exploring the challenges and strengths of mothers with substance-problems living in a high-risk community. Journal of Family Studies, 1-23. https://doi.org/10.1080/13229400.2019.1584122

Ward, C. L., Makusha, T., \& Bray, R. (2015). Parenting, poverty and young people in South Africa: What are the connections? South African Child Gauge, 69-74.

World Health Organization. (2009). Violence prevention: Preventing violence by developing life skills in children $\&$ adolescents. Geneva.

\section{Copyrights}

Copyright for this article is retained by the author(s), with first publication rights granted to the journal.

This is an open-access article distributed under the terms and conditions of the Creative Commons Attribution license (http://creativecommons.org/licenses/by/4.0/). 